\title{
Understanding employee resourcing in construction organisations
}

Abstract

In recent years the literature on employee resourcing has consistently advocated the importance of adopting a holistic, strategic approach to employee deployment decision-making rather than adopting a reactive needs-based approach. This is particularly problematic in construction where the multi-project environment leads to constantly changing resource requirements and to changing demands over a project's lifecycle. This can lead to inappropriate decisions, which fail to meet the longer term needs of both construction organisations and their employees. A structured and comprehensive understanding of the current project team deployment practices within large construction organisations was developed. Project deployment practices were examined within seven case study contracting firms. The emergent themes that shaped the decision-making processes were grouped into five broad clusters comprising human resource planning, performance/career management, team deployment, employee involvement and training and development. The research confirms that a reactive and ad hoc approach to the function prevails within the firms investigated. This suggests a weak relationship between the deployment process and human resource planning, team deployment, performance management, employee involvement and training and development activities. It 
is suggested that strategic HR-business partnering could engender more transparent and productive relationships in this crucial area.

Keywords: Employee involvement, human resource management, recruitment, project team, strategic management

\section{Introduction: the project deployment challenge}

Given the multi-disciplinarity and temporality of construction project teams, strategic project team deployment represents a complex and problematic task for construction organisations. Whilst the increasing use of outsourcing and subcontracting has reduced directly employed human resource requirements, it has made project management more complex, with a resultant requirement for a more precise matching of management skills and competencies to project requirements (Loosemore et al, 2003). Indeed, given that management is the main scarce resource within contracting organisations (Hillibrandt and Cannon, 1990: 115), it could be argued that this process forms a key determinant of competitiveness for such firms. Managed effectively, employee resourcing can help to achieve organisational flexibility by providing access to a full range of skills that can be utilised for longer-term strategic planning.

In construction, managers attempt to achieve the best technical/ financial business outcomes through their deployment decisions (De Feis, 1987). This can, however, lead to a focus on the achievement of financial, programme and quality outcomes over other project performance criteria (Dainty et al, 2003). Consequently, current project human resource allocation decisions tend to be 
reactive rather than founded on the longer term reconciliation of project, employee and organizational needs (Raidén et al, 2006). This can lead to employee dissatisfaction and attrition (with a consequent recurrent demand to recruit), and inappropriate deployment decisions (with a consequent failure to achieve project objectives). The recursive impact of these factors effectively defines the resourcing function a reactive process of meeting short-term requirements rather than planning for the long term development of the organisation. This is particularly the case for the larger contracting organisations with a large portfolio of projects.

This paper presents the findings of research which examined the employee resourcing function within seven large, UK-based contracting organisations. An inductive research design was used to reveal five emergent themes that shape the resourcing decision-making processes and how they are managed by leading construction firms. By explaining the interplay of these factors through case examples the research exposes the complexity of the project team deployment process and some of the issues needing to be taken into account by construction firms.

\section{The resourcing function in construction}

In human resource management (HRM) terms, the processes underpinning the formation of bespoke teams and temporary organisational structures, recruitment and selection, careers, planning and flexibility are grouped under the 'employee resourcing' function (Pilbeam and Corbridge, 2006). This function focuses on strategically integrating managerial efforts to ensure the organisational staffing requirements are met. Essentially, its success is 
predicated on sourcing suitable numbers of people with the appropriate skills and then deploying them in the right places at a time they are required. To date, the research attention given to the employee resourcing function in the context of the construction industry has focused on particular component tasks (see for example Bresnen et al, 1985; Lockyer and Scholarios, 2007). These are usually discussed in isolation from other aspects of the function. Whilst this may reflect the approach adopted in practice, it is the antithesis of the strategic and integrated function advocated within the broader defining HRM literature (see Taylor, 2005).

The fragmented approach to resourcing in both research and practice has rendered it a largely reactive function. For example, research on the operational aspects, such as human resource planning, recruitment and selection, team deployment, performance managemenț and career developmenț regularly draws attention to "fire-fighting" as the dominant paradigm of HRM in the industry (see for example Lockyer and Scholarios, 2007). This negates the benefits of longerterm planning and more strategic approaches to meeting organisational workload requirements (see Laufer et al 1999; Loosemore et al 2003). The individual contributions in these areas are discussed below under the thematic headings derived from the research.

\section{HR planning}

Taylor (2005) notes a difference in the actual use of human resource planning techniques in organisations and the rhetoric advocated by the often quite outdated literature on the topic. There is a significant debate for and against HR planning in the context of modern, fast changing market place. The position for HR planning is illustrated in the range of outcomes for the activity; for example, recruitment needs and knowledge of the labour markets, directions for training 
and development, staff costing and redundancies. These measures make a clear contribution towards achieving business objectives. In addition, planning is actually ever more important in a turbulent environment; organisations should develop systems and controls that allow them a reasonable input toward controlling the environment, not just reacting to changes in it (Bramham, 1988; Laufer et al, 1999). In this way planning can help reduce uncertainty, introduce structure and create order and action. In contrast, those arguing the case against HR planning assert that it is not feasible to forecast the future with any accuracy.

Research on HR planning in the construction industry shows an evolution from a focus on quantitative manpower planning (Anderson and Woodhead, 1987) toward strategic planning based on interaction, commitment, motivation, management style and other 'softer' qualities (Maloney, 1997; Smithers and Walker, 2000). This emphasis reflects broader trends within the broader HRM literature. Nevertheless, many of the component functions of the resourcing process remain reactive (Lockyer and Scholarios, 2007). Clarke and Herrmann (2007: 513) reported that a third of firms have difficulties in recruiting managers and senior officials in construction. They also note half of the firms in their sample experiencing difficulties in recruiting site managers. While their figures are specific to the social housing sector, there is very little difference with earlier findings from general construction surveys (see for example CITB, 2002 and HBF, 2001). These problems call for greater integration of planning into other resourcing activities so that contingencies can be put in place. Although Clarke and Herrmann (2007) note an increase in the firms that have a policy and/ or a plan in place for recruitment (and retention), informal methods of attracting candidates dominate the industry. The task is usually managed by line managers rather than HRM specialists and personal introductions and contacts 
are an important source of recruitment at all levels (Lockyer and Scholarios, 2007). Central to fair and equitable practice in recruitment and selection is objectivity (Iles and Salaman, 1995), which is difficult to achieve through such informal routes.

\section{Team deployment}

Team deployment is the third staffing activity crucial to success in a projectbased organisation (Druker et al, 1996). The predominant view is that a combination of technical/ process oriented qualities and leadership capabilities focused on facilitating team interaction contribute to project success (Zaccaro et al, 2001). Many agree that it is the management team or project leader that is central to creating conditions necessary for effective co-operation, such as trust, motivation, communication, culture of learning and improvement (Walker, 1996; Odusami, 2002; Goldberg, 2003). Despite the recognised importance of teamwork for construction organisations little attention has been paid to the actual process of building or composing project teams. Some contractors are known to use typologies such as Belbin's (1991) team role model or Margerison and McCann's (1991) team management wheel, but explicit discussion on their application in dynamic resourcing contexts such as construction is absent from the literature.

\section{Performance management and career development}

Performance management in the context of HRM refers to a strategic and integrated approach to improving the performance of people by developing the capabilities of individuals and teams (Armstrong, 2001: 467 c.f. Armstrong and Baron, 1998). Three distinct approaches to understanding the link between people management practices and organisational performance have emerged over the last decade: HR bundles (MacDuffie, 1995) akin to the universalist/ best 
practice approach to strategy, contingency or best fit approach and the $_{1}$ resource based view of the firm. The bundles approach focuses on creating an internal fit through the application of selected critical policies and practices that are mutually reinforcing (see for example Pfeffer, 1998; Wood and de Menezes, 1998). Their collective input is thought to have more impact on performance than the application of some of these in isolation. In contrast, the contingency approach focuses on fit with business strategy and identification of the sector specific people management practices. Finally, the resource based view of the firm looks at each organisation as a unique and complex whole. Purcell (1999) suggests that the latter is a more useful approach to people-performance analysis as it looks beyond the HRM policies to their implementation, change management and organisational context more broadly. Clearly each perspective has a different focus, but recent research suggests that all of them have a common theme: commitment (see Torrington et al, 2005). Indeed, commitment is central to analysis of HRM in many levels (see Guest, 1998; Watson, 2005).

\section{Employee involvement}

Employee involvement is a concept that has actively driven the agenda for greater staff commitment and participation through increasing employee voice and decision-making power. In essence, it is about increasing organisational effectiveness through manager and employee collaboration and through sharing power and control. In practice employee involvement takes a variety of forms, but Corbridge and Pilbeam (1998) provide a grouping of five categories:

- Downward communication in the form of reports, newspapers, videos, presentations, team briefings

- Upward problem-solving via suggestion schemes, quality circles, attitude surveys 
- Task participation via job rotation, job enrichment, teamworking, semiautonomous work groups

- Consultation and representative participation, e.g. joint consultation, informal discussions between managers and employees/ their representatives

- Financial participation in the form of profit-sharing schemes or employee share ownership plans.

Different types of employee involvement are often found to co-exist, particularly within organisations where it is a central element of the overall management style. Perhaps the most common types are downward communication, consultation and representative participation, and financial participation. However, in construction organisations explicit evidence of employee involvement is limited (Santos and Powell, 2001).

\section{Training and development}

One other area of HRM is closely related to the employee resourcing activities discussed above and very important for construction organisations: training and development (Yankov and Kleiner, 2001). Generally organisations take either a needs driven approach, an opportunistic approach or a proactive approach to human resource development strategy (Luoma, 2000). A needs-driven approach is perhaps the most common, where training and development are used in a reactive way to support the implementation of business strategy. The opportunistic approach focuses on the application of external ideas and developments (that originate from benchmarking, networking and academic/ practitioner publications) in the organisation in a general way. This approach may be reactive or proactive. Clearly, the proactive approach focuses on 
preparing for the future needs of the organisation. This approach is based on the concept of the 'resource based view of the firm' (as alluded to above, this view suggests each organisation is a complex and unique whole and thus great emphasis is placed on the context). Literature on training and development in the construction industry paints a rather pessimistic view of investment in this area within the industry. For example, the up-take of the Investors in People (liP) standard is low (Strategic Forum for Construction, 2002). This is said to reflect the industry's low commitment to human resource development (Dainty et al, 2000).

Whist the preceding review has described the component functions of the resourcing function, the literature provides few insights into how such processes are enacted in construction and moreover, how effective firms are at implementing the functions in such a way that they become mutually reinforcing. Hence, the research aim was to develop a structured and comprehensive understanding of the current project team deployment practices within large construction organisations through an examination of how this function is currently managed.

\section{Research design and methodology}

An interpretative approach was adopted within a case study design.

$\underline{\text { Interpretative research seeks to understand human experiences at a holistic }}$ level. This type of approach lends the research strength in focus on meanings (rather than facts), looking at the totality of each situation (rather than reducing phenomena to its simplest elements) and facilitating a study of the processes and issues from the perspective of the participants (rather than a pre-determined 
and -defined list of variables) (Bryman, 1989). Focus on meanings seeks to develop an understanding of how for example the employee resourcing processes are carried out in addition to the knowledge (fact) that they are carried out. Clearly such a subjective, context specific, approach has low external validity but "methodological trustworthiness" is established through reliability and construct validity in the case study design (see Healy and Perry, 2000; Yin, 1994). This is not to say that theory-testing should not be done; only the theory or model of current practice has to be built before its generalisability to a population is tested (Healy and Perry, 2000: 123).

Seven organisations took part in the study, each employing 1,000-2,000 professional/ managerial staff with a mean turnover of $£ 1,110$ million. The organisations were selected because of their track record on good people management practice. This eliminates null results (Purcell et al, 2003). The data collection was carried out using convergent interviews (Rao and Perry, 2003). This is an inductive, qualitative method particularly suited to investigating underresearched areas. It includes a series of semi-structured, in-depth discussions with experts. Each interview builds on the issues raised in previous interviews, to find agreements and disagreements with explanation between the interviewees. The interviews stop when stability (data saturation) is reached (c.f. Glaser and Strauss, 1967). This continuous refinement of focus allows for method flexibility. In the early stages of theory building not much is known about the topic area and qualitative methods are ideally suited to refining the research issues and reducing uncertainty. However, in an attempt to deal with potential interviewer bias, convergent interviewing incorporates structured data recording and analysis processes. Relevant to this research was pre-testing piloting and refinement of the interview schedules (which are an integral part of the convergent interviewing process as explained above); tape recording, verbatim 
transcription and tiered coding of each interview; careful interpretation of the data; and selection of representative quotes to connect with the frames of reference used by the participants.

The interviews focussed on establishing the organisational strategies, policies and operational practices. Since little a priori knowledge of construction resourcing was available broad range of issues for investigation were organised under four main headings: HRM strategy, project requirements, interpretation of policy into practice and employee needs and preferences. Specific probes addressed both strategic and operational considerations such as work design, human resource planning and project deployment (HRM strategy); performance management, recruitment and training (interpretation of policy into practice);

Deleted: project success criteria, skills and competencies (project requirements);

[insert Table 1 here]

In qualitative research like this the sampling method is purposeful (rather than random) (Patton, 1990). A 'snowball' sampling technique is appropriate where research is concerned with small, specialised population who are knowledgeable about the topic. Here research initially starts with a diverse sample of experts, and after each interview the interviewee is asked to recommend other people who should be interviewed. In total, the sample consisted of four divisional directors, eight operational senior managers and 13 HR staff across the seven companies. Each interview lasted approximately one and a half hours. The data were analysed using multiple analytical tools and techniques. These included NVivo qualitative analysis software package, summary statement matrices (Miles and Huberman, 1994) and thematic 
analysis (Boyatzis, 1998). The coding process identified important themes and revealed a structure appropriate for analysis after Taylor (2005). Throughout the data collection and analysis NVivo supported effective cross-checking of themes and helped in modelling of the ideas. The key findings are presented below along with illustrative verbatim quotations to convey the approaches and scale of the challenges identified through the data collection.

\section{Findings and discussion}

The findings are presented under headings inductively derived from the data. Following an explanation of the strategic positioning of the HR function, the issues that emerged have been grouped under the thematic headings used in the literature review above: human resource planning, recruitment and selection, team deployment, performance management, employee involvement and training and development.

\section{Positioning of the HR function}

In general, the evidence across the seven case study organisations reflected the practice identified within the literature summarised above. The organisations had well-established HR policies, but the HR specialists' role tended to revolve around reactively "fire-fighting" problems as they occurred and dealing with their consequences, rather than getting involved at the outset as to prevent the problems from occurring in the first place. One HR manager explained: 
"HR is dealing with the wrong end of the business. Our main problems are associated with terminations: industrial tribunals, compensation and lots of hassle. HR does not get an opportunity to input to line management decision-making as to the suitability of the people they are taking in. This is wrong. If you are trying to run a successful business, it is the people that you bring in that are critical. Then we wouldn't need to get involved in so many negative exit situations."

Many of the day-to-day HR responsibilities were devolved to the operational line managers and so they formed the main point of contact for project-based staff in terms of developmental and promotional opportunities, project/ team deployment issues and other HR related queries. Moreover, current practice was characterised by informality:

"I haven't had any formal [interviewing] training. I have been through booking schemes and trial and error. But I suspect I have not been allowed into this position and been promoted to do those interviews until I have demonstrated that I have a fair chance of getting the right type of people because of my background, I know the culture and I have been developed as a senior manager in line with the rest of the senior managers with a common focus, common ambition." (Operational senior manager)

The informal outlook was combined with reactive approach. One HR manager described the attitude their line managers was "if it doesn't work out, just let them go". In addition, whilst the devolution of HR responsibilities was useful in easing employee communications, it created a project-specific and very immediate focus, within which it is difficult to formulate long-term and strategic 
vision for the organisation as a whole. Thus, the greatest employee resourcing specific issue seemed to stem from the diversity of local practices found at a divisional or project level. At the organisation level strategic intention was often very positive. Senior managers attempted to plan for the human resource requirements and the organisational climate projected an open and friendly working environment. The informal culture, which emphasised divisional/departmental loyalty and close working relationships between staff and their line managers, could not serve as a basis for translating this intention into effective managerial practice.

\section{Human resource planning}

Human resource planning tended to be focused on seeking solutions to staffing needs based on one year forecasts. Some specific techniques in use included "what if" scenarios and numerical forecasting. The objective was to assess the current staff profile in relation to the estimated future needs and requirements. Succession planning was commonly informal and managed by the organisations' divisional directors. Fast track progression opportunities were offered to attract and retain suitable candidates. However, although this had allowed for fresh ideas to be brought into management decision-making, at the same time it had also resulted in resentment from some existing staff members and even to certain individuals suffering from stress related problems. A senior contracts manager referred to one of his employees on such a scheme:

"The question is how far can you stretch a person... we have had, luckily only a small number of incidents with individuals suffering from stress related illnesses. But once you have somebody it is horrific. I have got an individual working on one job who hit exactly that at Christmas. We put a 
lot of time into giving him support, bringing him back. We put him into a job role that he was comfortable with. Now, I did his appraisal last week and it would appear that he is back on strain now. I believe we might have pushed him too hard again... Somebody who is on the surface capable of taking anything really and then in front of you snaps. That is one of my key issues with human resources..."

Strategic planning was identified as a key requirement for employee resourcing decision-making. It was highlighted as a route to organisational flexibility and effective management of change via a culture founded on trust, openness, partnering, employee involvement and an individualistic management style. This supports the work of Bramham (1988) and Laufer et al (1999) who argue that effective planning is particularly important within the dynamic project-based sectors, in that it can help reduce uncertainty, introduce structure and create order and action. Table 2 summarises the key features of current organisations practice and the strategic importance of the function derived from literature.

[insert Table 2 here]

\section{Recruitment and selection}

The main responsibility for recruitment and selection was devolved to operational line management and isolated from human resource planning. The informal way in which recruitment was handled had resulted in highly fragmented systems of operation within local divisions/projects. Vacancy information was rarely available company-wide and thus employees were not always aware of potential opportunities beyond their divisions. Equally, the widest possible pool of candidates was not attracted outside the organisation 
due to a reliance on word-of-mouth recruitment and headhunting. All seven organisations had experienced difficulties in recruiting appropriate numbers of suitably qualified staff and mentioned clients becoming increasingly demanding.

The informality of the organisations' recruitment and selection practices strengthens the evidence provided by the industry literature, which highlights personal introductions common and important source of recruitment at all levels (Druker and White, 1996; Lockyer and Scholarios, 2007) and selection methods restricted to interviews and assessment centres (Langford et al, 1995; Loosemore et al, 2003). This undermines the vital importance of objectivity and effective recruitment and selection processes, which can be achieved via reconciliation of the human resource planning outcomes with the shorter-term operational conditions. Table 3 summarises the key features of current organisations practice and the strategic importance of the function derived from literature.

[insert Table 3 here]

\section{Team deployment}

Team formation and deployment was considered to be the most important of all the aspects considered under employee resourcing:

"The real issue in construction is whether you can form good teams or not. This makes the difference between success and failure. Actually half of your long-term success is in the strength of your team". (Senior operational manager) 
This supports Druker et al (1996), Walker (1996) and Goldberg (2003) among others who identify teamwork as a key to competitive advantage, powerful motivator and the foundation for co-operative working culture. Despite this, much of the task was managed on an ad hoc basis, and in response to immediate project start requirements or problems identified within existing projects. The process relied upon senior managers' abilities to fully understand the capabilities of their staff, a task that was increasingly difficult given the rapid intake (and turnover) of staff in the current competitive labour market. One senior estimator explained:

"We probably do it from a gut feel really. I know the company, I have worked here for 27 years. You know people. There are newcomers, but I know the key players. It is all in here [pointing to his head]..."

"Availability" was the predominant factor determining the allocation of staff to a project. This was followed by other variables that focused on meeting the organisational/ project requirements: the potential team members' experience and client preferences. As well as selecting the key personnel to head a project, ensuring a balance between the team members' strengths and weaknesses and their willingness to work together for a common aim was considered crucial. Only after these had been taken into account were the individual employees' needs and preferences considered. The HR function had very little direct input into the team deployment process. In some instances senior managers requested HR information to substantiate their plans (for example training records were included in some tender notes). This suggests that the HR role js akin to an administrative function rather than being viewed as a strategic business partnership (see Ulrich, 1997; Boxall and Purcell, 2007). A partnering 
awareness of HR issues and thus a balanced approach to deployment decisionmaking.

The ad hoc and subjective nature of the deployment decision-making demanded extensive flexibility from the employees. Managers attempted to compensate informally for this, for example by allowing employees to finish early if a project was progressing as planned. No formal means of recognition for the employee flexibility were in place. Many suggested that flexibility was an integral aspect of the nature of work within the industry, and thus a "requirement" rather than an act of commitment or loyalty. Table 4 summarises the key features of current organisations practice and the strategic importance of the function derived from literature.

[insert Table 4 here]

\section{Performance management and career development}

An analysis of the performance management and career development activities support the view discussed above; that current practice is dominated by largely informal and reactive processes. Much of the responsibility for the management and development of staff careers was devolved to the individual, a trend noted by Thite (2001). Managers guided their employees' decision-making only as far as the organisational/ project requirements demanded immediate solutions and to which a career move of an identified individual was the optimum solution.

Recent organisational growth had resulted in many staff being promoted rapidly if they demonstrated appropriate leadership abilities. This has provided ambitious individuals with the opportunity to further their careers at a fast pace and realise their aspirations far more quickly than would have been possible 
during a stable or downturn period. However, there were concerns as to the long-term viability of such practices, as the organisation will not be able to fulfil the employees' raised aspirations and expectations which js likely to have detrimental effect on staff turnover. The following quote from a project manager illustrates this concern:

"I am a project manager and I have said to him [the manager] I want to be a senior project manager, but we only have two in the company. Now whether there is a place for a third... you have to look at it from their point of view and be realistic. But then you look at it from my point of view and I couldn't care less how they react. I am good at the job and I can do the job and I need an opportunity to show them I can do the job. If they don't give me the opportunity, [there are] plenty of others. I mean, people ring in every week, we are being constantly headhunted..."

On the other hand, the high level of expectation on both new and existing managers had resulted in certain individuals suffering from stress-related problems, as already discussed above. Thus, senior managers were faced with the negative consequences of stress related illnesses and the associated costs of time taken off sick, reduced productivity and morale, possible loss of valuable members of staff and the subsequent costs of recruitment and training of replacement personnel.

The performance appraisal system formed the only formal means of selecting people for promotion. The annual appraisal interviews provided an opportunity for discussing potential progression solutions and aided assessing individuals' current job performance, developing personal development plans and recording 
employees' aspirations and preferences. However, the data gathered appeared to have little influence on the resourcing decision-making processes:

"The objective part is: am I doing what I am supposed to be doing, if not what am I going to do about it... so that is measurable. Then there is the subjective part, which is what does he think of me, what do I think of him, what do I think he thinks of me... And that is it. Then we all sign it and put it away for a year." (Chief estimator)

This type of largely informal and reactive view matches most closely with the contingency approach to strategic performance management. Many organisations are clearly aiming toward the resource based view of the firm but their short-term focus holds back the achievement of truly holistic approach. Table 5 summarises the key features of current organisations practice and the strategic importance of the function derived from literature.

[insert Table 5 here]

\section{Employee involvement}

Employee involvement and participation in team deployment or other employee resourcing decision-making was minimal. Indeed, organisational practices were limited to financial incentives (in the form of the bonus scheme and individual pay negotiations) and informal employee-manager relationships. Many of the managers also mentioned downward communication. A team briefing structure was said to cascade down throughout the organisations. The employees, however, suggested that the team briefings were infrequent and ineffective. This 
defeated the employee involvement purposes of the downward communication, thus making it a pure information delivery mechanism.

This type of approach to employee involvement is common throughout all sectors (Marchington, 2005). Little evidence of upward problem-solving or task participation was found, although literature suggests these as effective means toward enhanced employee performance and organisational success (Marchington, 2005). Moreover, the research findings support the construction literature, which suggests the prevalence of poor employee involvement practices within the industry.

This is surprising taking into account the emphasis placed on informal culture and individualistic management style in relation to many other aspects of employee resourcing. It may be that an ideology of employee involvement presents an attractive framework for managerial decision making, but that the operational reality does not allow for effective delivery of this aim. Table 6 summarises the key features of current organisations practice and the strategic importance of the function derived from literature.

[insert Table 6 here]

\section{Training and development}

Training and development issues formed one of the key topics discussed within the interviews. Frequent and varied formal training courses and regular updates were widely available. Training toward professional qualifications and gaining chartered status as well as continuous professional development (CPD) were high priorities especially within the management ranks. Indeed, many 
commented on the extensive opportunities available within their organisations and the substantial benefits these bring in terms of employee involvement and commitment. Training needs were identified in two-way discussions and recorded in personal development plans. These discussions included opportunities to highlight personal preferences, although managers also actively suggested different options. Informal mentoring/ coaching arrangement supported the socialisation and induction of new employees.

The prominent approach to training and development combined elements of the needs based approach and opportunistic approach. Table 7 summarises the key features of current organisations practice and the strategic importance of the function derived from literature.

[insert Table 7 here]

\section{Conclusion}

An ad hoc and largely reactive approach to employee resourcing prevails within that a the case study construction organisations. This leads to a tendency amongst managers and HRM specialists to view resourcing as responsive with little opportunity to contribute toward strategic planning. This situation is exacerbated by the various components of the resourcing function being poorly integrated. For example, recruitment and selection was devolved to operational line management in isolation from the HR planning function. This resulted in highly fragmented systems of operation within local divisions/projects, which in turn 
contributed to difficulties in filling vacancies. Similarly, team deployment was managed on an ad hoc basis, largely in response to immediate operational requirements. The process relied upon senior managers' knowledge of their staff, which was difficult to maintain given the high levels of turnover and recruitment. Overall, the role of HR appears peripheral to the resourcing function. Hence, it was difficult to provide strategic input to the decision-making processes.

Addressing the issues raised in this research demands a more systematic proactive approach towards the resourcing function. The need for better integration of the components of the function and for taking a more strategic view of resourcing both suggest the relevance of the business partner model (c.f. Ulrich 1997). This provides a firm basis for the HR-line collaboration necessary to deliver a stronger, more competitive business and meet business targets through effectively deployed workforce.

\section{References}

Anderson. S.D. and Woodhead, R.W. (1987) Project manpower management: decision-making processes in construction practice, John Wiley \& Sons, Smith, N. (1993) Making it happen: managing performance at work, Prentice Hall, Sydney New York

Armstrong, M. (2001) Human Resource Management Practice, Kogan-Page, London

Armstrong, M. and Baron, A. (1998) Performance Management: The new realities, Institute of Personnel and Development, London

Baruch, Y. (2003) Career systems in transition, a normative model for organisational career practices, Personnel Review, 32(2), 231-251

Formatted: Font: Italic 
Belbin, R.M. (1991) Management teams: why they succeed of fail, ButterworthHeinemann, Oxford

Bourne, L. and Walker, D.H.T. (2005) The paradox of project control, Team Performance Management, 11(5/6), 157-78

Boxall, P. and Purcell, J. (2007) Strategy and human resource management (Management, work and organisations) $2^{\text {nd }}$ Edn, Palgrave Macmillan, Basingstoke

Boyatzis, R.E. (1998) Transforming qualitative information: thematic analysis and code development, SAGE, Thousand Oaks, CA

Bramham, J. (1988) Practical manpower planning, $4^{\text {th }}$ Edn, IPM, London

Bresnen, M. J., Wray, K. Bryman, A., Beardsworth, A., Ford, J. and Keil, E. (1985) The flexibility of recruitment in the construction industry: formalisation or recasualisation? Sociology, 18(1), 108-24

Cheng, M., Dainty, A. and Moore, D. (2007) Implementing a new performance system within a project-based organisation, a case study, International Journal of Productivity and Performance Management, 56(1), 60-75

Cheng, M., Dainty, A.R.J. and Moore, D.R. (2005) Towards a multidimensional competency-based managerial performance framework, a hybrid approach, Journal of Managerial Psychology, 20(5), 380-95

CITB (2002) Employers' skill needs survey, CITB, Bircham Newton

Clarke, L. and Herrmann, G. (2007) Skill shortages, recruitment and retention in the house building sector, Personnel Review, 36(4), 509-527

Deleted: Clark, I. and Colling, T. (2005) The management of human resources in project management-led

Corbridge, M. and Pilbeam, S. (1998) Employment resourcing, Harlow: Financial Times/ Prentice Hall 
Dainty, A.R.J., Bagilhole, B.M. and Neale, R.H. (2000) The compatibility of construction companies' human resource development policies with employee career expectations, Engineering, Construction and Architectural Management, 7(2), 169-78

Dainty, A.R.J., Cheng, M. and Moore, D.R. (2003) Refining performance measures for construction project managers: an empirical evaluation, Construction Management and Economics, 21(2), 209-18

Dainty, A.R.J., Neale, R.H. and Bagilhole, B.M. (1999) Women's careers in large construction companies: expectations unfulfilled? Career Development International, 7(4), 353-57

De Feis, G. (1987) People: an invaluable resource, Journal of Management in Engineering, 3(2), 155-62

Druker, J. and White, G. (1995) Misunderstood and undervalued? Personnel Management in Construction, Human Resource Management Journal, 5(3), 77-91

Druker, J. and White, G. (1996) Managing people in construction, IPD, London

Druker, J., White, G., Hegewisch, A. and Mayne, L. (1996) Between hard and soft HRM: human resource management in the construction industry, Construction Management and Economics, 14(5), 405-16

Fellows, R., Langford, D., Newcomber, R. and Urry, S. (2002) Construction management in practice, $2^{\text {nd }}$ Edn. Blackwell, Oxford

Glaser, B.G. and Strauss, A.L. (1967) The discovery of grounded theory: strategies for qualitative research, Aldine, New York 
Goldberg, S. (2003) Team effectiveness coaching: an innovative approach for supporting teams in complex systems, Leadership and Management in Engineering, 3(1), 15-17

Guest, D. (1998) Beyond HRM: commitment and the contract culture, in Sparrow, P. and Marchington, M. (eds), Human resource management: the new agenda, Financial Times Pitman, London

HBF (2001) Employment survey, House Builders' Federation, London

Healy, M. and Perry, C. (2000) Comprehensive criteria to judge validity and reliability of qualitative research within the realism paradigm, Qualitative Market Research: An International Journal, 3(3), 118-26

Hillebrandt, P. M. and Cannon, J. (1990) The Modern Construction Firm, Macmillan, Hampshire

Iles, P., Salaman, G. (1995), Recruitment selection and assessment, in Storey, J. (Eds), Human Resource Management: A Critical Text, Routledge, London

Langford, D., Hancock, M., Fellows, R. and Gale, A. (1995) Human resource management in construction, Longman, Harlow

Laufer, A., Woodward, H. and Howell, G. (1999) Managing the decision-making process during project planning, Journal of Management in Engineering, 15(2), $79-84$

Lockyer, C. and Scholarios, D. (2007) The "rain dance" of selection in construction: rationality as ritual and the logic of informality, Personnel Review, 36(4), 528-48

Loosemore, M., Dainty, A. and Lingard, H. (2003) Human resource management in construction projects, strategic and operational approaches, Spon Press, London 
Luoma, M. (2000) investigating the link between strategy and HRD, Personnel Review, 29(6), 769-790

MacDuffie, J. (1995) Human resource bundles and manufacturing performance: organizational logic and flexible production systems in the world auto industry, Industrial and Labor Relations Review, 48(2), 197-221

Maloney, W. (1997) Strategic planning for human resource management in construction, Journal of Management in Engineering, 13(3), 49-56

Marchington, M. (2005) Employee involvement: patterns and explanations, In Hyman, J., Thompson, P. and Harley, B. (eds.) Participation and democracy at work, Palgrave, Basingstoke

Margerison, C. and McCann, D. (1991) Team management: practical approaches, Mercury, London

Miles, M.B. and Huberman, A.M. (1994) Qualitative data analysis, $2^{\text {nd }}$ Edn. SAGE, Thousand Oaks, CA

Nesan, L.J. and Holt, G. (1999) Empowerment in construction: the way forward for performance improvement, Research Studies Press, Baldock

Odusami, K.T. (2002) Perceptions of construction professionals concerning important skills of effective project leaders, Journal of Management in Engineering, 18(2), 61-67

Patton, M.Q. (1990) Qualitative evaluation and research methods, $2^{\text {nd }}$ Edn, SAGE, Newbury Park

Pfeffer, J. (1998) The human equation, Harvard Business School Press, Boston Pilbeam, S. and Corbridge, M. (2006) People resourcing: contemporary HRM in practice, $3^{\text {rd }}$ Edn. Financial Times Prentice Hall, Harlow 
Purcell, J. (1999) Best practice and best fit: chimera or cul-de-sac? Human resource Management Journal, 9(3): 26-41

Purcell, J., Kinnie, N., Hutchinson, S. Rayton, B. and Swart, J. (2003) Understanding the people and performance link: unlocking the black box, CIPD, London

Raidén, A.B., Dainty, A.R.J. and Neale, R.H. (2006) Balancing employee needs, project requirements and organisational priorities in team deployment, Construction Management and Economics, 24(8), 883-95

Rao, S. and Perry, C. (2003) Convergent interviewing to build a theory in underresearched areas: principles and an example investigation of internet usage in inter-firm relationships, Qualitative Market research: An International Journal, 6(4), 236-247

Smithers, G. and Walker, D. (2000) The effect of the workplace on motivation and demotivation of construction professionals, Construction Management and Economics, 18(7), 833-41

Strategic Forum for Construction (2002) Accelerating change, Rethinking Construction, London

Taylor, S. (2005) People resourcing, $3^{\text {rd }}$ Edn. CIPD, London

Teece, D., Pisano, G. and Shuen, A. (1997) Dynamic Capabilities and Strategic Management, Strategic Management Journal, 18(7), 509-533

Thite, M. (2001) Help us but help yourself: the paradox of contemporary career management, Career Development International, 6(6), 312-317

Torrington, D., Hall, L. and Taylor, S. (2005) Human resource management, $6^{\text {th }}$ Edn. Financial Times-Prentice Hall, Harlow 
Ulrich, D. (1997) Human resource champions: the next agenda for adding value and delivering results, Harvard Business School Press, Boston, MA

Walker, D.H.T. (1996) Characteristics of winning construction management teams, In Langford, D.A. and Retik, A. (eds) The organisation and management of construction: shaping theory and practice, 1, 321-34

Watson, T. (2005) Organisations, strategies and human resourcing, In Leopold, J., Harris, L. and Watson, T. (eds.) The strategic managing of human resources, Financial Times Prentice Hall, Harlow, pp. 6-33

Wood, S. and de Menezes, L. (1998) High commitment management in the UK: evidence from the Workplace Industrial Relations Survey ad employers' manpower and skills practices survey, Human Relations, 51(4), 485-515

Yankov, L. and Kleiner, B.H. (2001) Human resources issues in the construction industry, Management Research News, 24(3/4), 101-105

Yin, R.K. (1994) Case study research: design and methods, $2^{\text {nd }}$ Edn, SAGE, London

Zaccaro, S., Rittman, A. and Marks, M. (2001) Team leadership, The Leadership Quarterly, 12, 451-483 
Table 1: Examples of the research interview questions

\begin{tabular}{|c|c|c|}
\hline Heading & $\begin{array}{l}\text { Specific } \\
\text { considerations }\end{array}$ & Examples of interview questions/ probes \\
\hline \multirow[t]{2}{*}{ HRM strategy } & HR planning & $\begin{array}{l}\text { - Is there a HR strategy in place? } \\
\text { - What are the core objectives of the strategy? } \\
\text { - How does this translate into practice? } \\
\text { - What are the current [3 key] resourcing issues? }\end{array}$ \\
\hline & $\begin{array}{l}\text { Project } \\
\text { deployment }\end{array}$ & $\begin{array}{l}\text { - How do you deploy staff to projects? } \\
\text { - Do you take account of training and } \\
\text { development (and/ or other areas of HRM) in the } \\
\text { process? How? }\end{array}$ \\
\hline \multirow[t]{3}{*}{$\begin{array}{l}\text { Interpretation } \\
\text { of policy into } \\
\text { practice }\end{array}$} & $\begin{array}{l}\text { Performance } \\
\text { management }\end{array}$ & $\begin{array}{l}\text { - Do you take account of performance } \\
\text { management in the deployment process? How? } \\
\text { - What determines performance targets? } \\
\text { - How flexible are these? }\end{array}$ \\
\hline & $\begin{array}{l}\text { Recruitment } \\
\text { and selection }\end{array}$ & $\begin{array}{l}\text { How does recruitment and selection interface } \\
\text { with the deployment process? }\end{array}$ \\
\hline & $\begin{array}{l}\text { Training and } \\
\text { development }\end{array}$ & $\begin{array}{l}\text { - Do you encourage systematic training and } \\
\text { development through the resourcing process? } \\
\text { How? }\end{array}$ \\
\hline \multirow[t]{2}{*}{$\begin{array}{l}\text { Employee } \\
\text { needs and } \\
\text { preferences }\end{array}$} & $\begin{array}{l}\text { Employee } \\
\text { involvement }\end{array}$ & $\begin{array}{l}\text { - Do you consider employee involvement in the } \\
\text { resourcing decision-making? How? } \\
\text { - Do you encourage flexibility through the } \\
\text { resourcing decision-making? How? }\end{array}$ \\
\hline & $\begin{array}{l}\text { Work-life } \\
\text { balance? }\end{array}$ & $\begin{array}{l}\text { - Do you consider employee work-life balance? } \\
\text { - How? } \\
\text { - What are the key issues? }\end{array}$ \\
\hline
\end{tabular}


Table 2: Human resource planning

\section{Current practice}

- Techniques in use: "what if" scenarios and numerical forecasting

- Informal succession planning, fasttracking

- Owned by operational managers

- Strategic planning central issue in resourcing decision-making
Strategic importance of the function

- Potential route to organisational flexibility and effective management of change

- Outcomes: recruitment needs, directions for training, costing, etc.

- Can help reduce uncertainty, introduce structure, create order and action

- HR-business planning integration

- Cultural management 
Table 3: Recruitment and selection

Current practice

- Isolated from human resource planning

- Devolved to line management

- Informal, fragmented

- No vacancy information available group-wide

- Word-of-mouth and headhunting prominent methods
Strategic importance of the function

- Reconciliation of human resource planning outcomes with short-term operational conditions

- Ensure appropriate supply of skilled staff to the organisation

- Objective decision-making 
Table 4: Team deployment

Current practice

- Ad hoc, reactive to immediate project start requirements or problems

- Fragmented, isolated from other resourcing activities

- Staff availability number one selection criteria in team formation; employee needs and preferences neglected

- Reliance on managers' subjective knowledge

- Flexibility managed informally
Strategic importance of the function

- The key to competitive advantage and effective co-operation

- Powerful motivator

- Supports the achievement of the project/ organisational goals leading to improved productivity

- The intangibles of human interaction separate average performance from outstanding execution 
Table 5: Performance management

Current practice

- Informal and reactive

- Importance of incorporating comprehensive range of factors into the decision-making undermined

- Responsibility for career management on employee, managerial guidance only in relation to immediate organisational/ project requirements

- Long-term consequences overlooked

- Appraisal paper-based, process duplication
Strategic importance of the function

- Integrated comprehensive strategy for maximising individual, team and organisational performance whilst facilitating employee career development

- HR bundles/ contingency approach/ resource based view of the firm

- Alignment of the strategic HRM practices with the organisational strategic decision-making

- Outcome: commitment 
Table 6: Employee involvement

\section{Current practice}

- Not included in the central team deployment function

- Limited to financial incentives, informal employee-manager relationships and some downward communication
Strategic importance of the function

- Approach to increasing organisational effectiveness through manager and employee collaboration and sharing power and control

- Downward communication, upward problem-solving, task participation, consultation, financial participation 
Table 7: Training and development

\section{Current practice}

- Frequent and varied formal training courses, regular up-dates

- Managers encourage attendance

- Training needs discussed via personal development plans

- Opportunity to highlight personal preferences

- Managers suggest/ offer range of options

- More senior/ longer serving members take [informal] responsibility to guide new recruits, team members and recently promoted personnel via mentoring/coaching
Strategic importance of the function

- Outcome: well trained staff that have the required skills and qualifications to carry out their duties

- Employees realise organisational commitment and opportunities Personalised and tailored solutions

- Employee involvement and commitment

- Support for career management

- Needs driven/ opportunistic/ proactive approach 